\title{
Finite element analysis for components force of flexural rubber joint
}

\author{
Hong $\mathrm{HE}^{1, \mathrm{a}}$, Xiaoqin $\mathrm{Li}^{1}$, Shenjun $\mathrm{Gao}^{2}$ \\ ${ }^{1}$ Electromechanic Engineering College, Beijing University of Chemical Technology, Chaoyang, Beijing, China \\ ${ }^{2}$ Shanghai Jingyi Rubber Technology Co., Ltd., Shanghai, China
}

\begin{abstract}
Flexible rubber joint is an important connecting pipe fitting in ship and chemical industry. However, the problems existing in its application, especially the stress distribution for each component of rubber joint structure, were lack of theoretical analysis. Therefore the finite element model of rubber joint was established according to its structure in this study. With the help of software, the stress characteristics of rubber joint under the axial tension and periodic dynamic load were analysed with the standard maximum internal pressure load and flanges bolt pretension together. The calculation results showed that the order of maximum stress in rubber joint components from big to small was: reinforcement ring, cord layer and rubber skeleton. In order to reduce the stress value at the weak area in the rubber components, the angles of the cord were studied and found that when the cord angle were $60 \%-60^{\circ}$ for $1,3,5 / 2,4,6$ layer respectively, the maximum stress value for the reinforcement ring and cord fabrics were reduced obviously. After the life computation by the software, it was confirmed that the cord angle arrangement $60 \%-60^{\circ}$ for cord layers could significantly improve the service life of the rubber joint.
\end{abstract}

\section{Introduction}

Flexible rubber joints, referred to as rubber joints, also known as rubber expansion joints, damping throats, etc., are commonly used to absorb displacement and reduce vibration in ship pipeline systems. In practical applications, the main problems of rubber joints were end leakage and rubber framework degumming and tearing. However, at present, domestic manufacturers mainly focuses on the use of $\mathrm{it}^{[1,2]}$ and lack of theoretical research. In order to find the failure cause of rubber joint, the finite element method was used to analyse the stress distribution inside the rubber joint components under the action of internal pressure and the load of $\mathrm{x}$ axial tensile displacement or the periodic $\mathrm{x}$ axial tensile displacement, and the fatigue life of the rubber joint was calculated by software so as to find the way to improve its service life.

\section{The establishment of finite element model for flexible rubber joint}

\subsection{Structure and Model establishment of Flexible Rubber Joint}

The single ball rubber joint was composed of three layers: inner, middle, and outer rubber layer, which was called the rubber framework. The middle layer was reinforced by cord fabric, and the flange fastening area rubber was reinforced with reinforcing rings, as shown in Figure 1. The rubber joint studied conform to the ministerial standard of Chemical Industry HG/T22892000 , the nominal diameter was $\varnothing 50 \mathrm{~mm}$, and the length was $100 \mathrm{~mm}$. The rubber frame's material was EPDM rubber. The polyester cord material was adopted for the cord layer, and the first to sixth ply cord layers were arranged in the radial direction. The reinforcing rings' material was carbon steel. Besides, the standard flanges were selected for connecting pipelines and fastening rubber joint

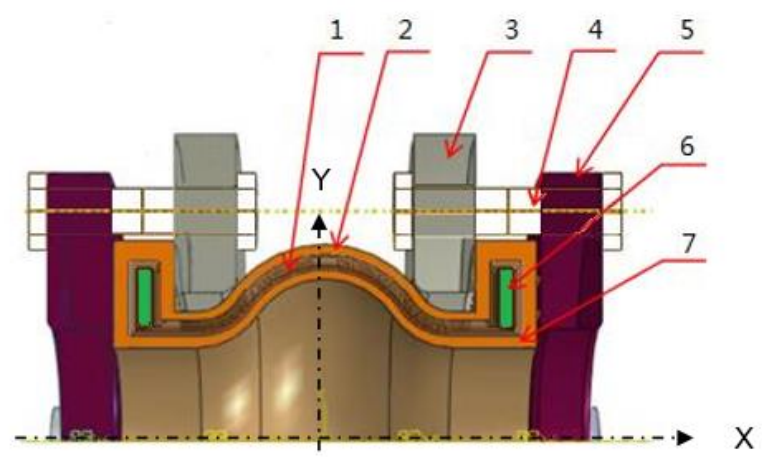

Figure.1 Structure of rubber joint

1 - Cord layers and Middle rubber layer; 2 - Outer rubber layer;

3 - Fastening flange; 4 - Bolts (M12); 5- Adapting flange; 6 - Reinforcing ring; 7 -Inner rubber layer.

Based on the structure of rubber joint above, the finite element geometric model was established. The cord fabric and reinforcing ring were embedded and bounded to the rubber middle layer and fastened area rubber respectively. Hexahedron element was chosen for the rubber framework, reinforcing rings, four connecting

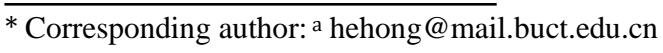


bolts and flanges. And the element types for above four components were: C3D8HR, C3D8R, R3D4 respectively. Meanwhile, surface element SFM3D4R was selected for the reinforced cord fabric. The total number of elements for rubber joint was 54010 .

When the flanges were fixed, the rubber in contact with the flange 3 and 5 would be tightened. There were relative displacement between the flange and the rubber joint. The relative displacement of rubber was small with adapting flange 5 and large with fastening flange 3, therefore surface-surface contact was chosen for flange and rubber joint with Coulomb friction type, the friction coefficient was 0.5 and 0.1 separately. The corresponding algorithms were selected as small slip algorithm and finite slip algorithm respectively.

\subsection{Material Parameters}

In this study, the sample from EPDM rubber which was the material of joint framework was stretched by uniaxial tension. And then the stress strain data obtained from the experiment were fitting by constitutive models for superelastic material. It was found that Yeoh model was a suitable model because it was well-fitted with the experimental data. Therefore Yeoh constitutive model was used to describe the mechanical behaviour of the rubber frame:

$$
W_{R}=C_{10}\left(I_{1}-3\right)+C_{20}\left(I_{2}-3\right)^{2}+C_{30}\left(I_{3}-3\right)^{3}
$$

Where, $W_{R}$ is the strain energy function. $I_{1} 、 I_{2} 、 I_{3}$ indicate the three strain invariants of rubber materials, respectively. The material constants obtained by fitting were $C_{10}=2.46072, C_{20}=0.748465, C_{30}=0.222202$.

The material parameters used for rubber framework, cord fabric, and adapting flange are shown in Figure.1.

Table 2. Material parameters for rubber joint's components

\begin{tabular}{|c|c|c|c|}
\hline $\begin{array}{c}\text { Component } \\
\text { Names }\end{array}$ & $\begin{array}{c}\text { Density/ } \\
\left(\mathbf{k g} / \mathbf{m}^{3}\right)\end{array}$ & $\begin{array}{c}\text { Elastic modulus } \\
/ \mathbf{M P a}\end{array}$ & $\begin{array}{c}\text { Poisson } \\
\text { ratio }\end{array}$ \\
\hline Rubber Frame & $1.32 \times 10^{3}$ & 16800 & 0.49 \\
\hline Cord Fabrics & $2.475 \times 10^{2}$ & 2200 & 0.4 \\
\hline $\begin{array}{c}\text { Reinforcing Rings } \\
\text { and Bolts }\end{array}$ & $7.85 \times 10^{3}$ & 206000 & 0.3 \\
\hline
\end{tabular}

The cord layer was embedded into the rubber framework by rebar. The cross-sectional area of the single cord was $0.3419 \mathrm{~mm}^{2}$, the spacing between each cord is $1.0 \mathrm{~mm}$ and the spacing between each layer is $0.8 \mathrm{~mm}$.

With the coordinates shown in Figure 1, on the projection plane $\mathrm{XOZ}$, angle between the cord and the positive $\mathrm{X}$ coordinate axis was called positive cord angle, or vice versa. The cord angles of the first, third, and fifth cord layer were $45^{\circ}$, and that of the second, fourth, sixth cord layers were $-45^{\circ}$.

\subsection{Boundary Loads}

As a connector in the pipeline system, rubber joints would be displaced by the impact of the fluctuation of the water flow and also absorb the vibration from the piping system. Therefore, the two situations of boundary loads on rubber joint were considered: axial displacement load and periodic force. According to the environmental protection product standard $\mathrm{HJ} / \mathrm{T}$ 3912007, the maximum axial displacement of the flexible rubber joint was determined to be $6 \mathrm{~mm}$ and the working pressure was $2.5 \mathrm{Mpa}$.

Based on the alternating excited force of the complex piping system and the allowable pressure unevenness for pipeline system ${ }^{[3]}$, the axial cyclic load on the rubber joints was determined, see Figure 2. The cyclic concentrated force was applied to the adapting flange 5 in fig.1.

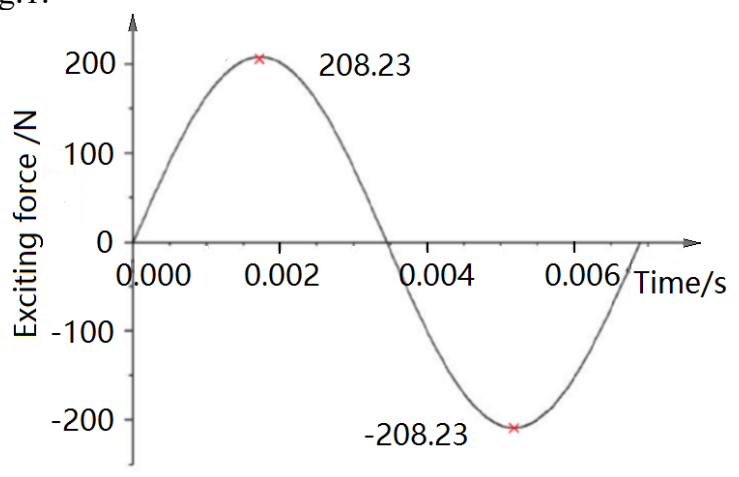

Figure 2 Exciting force curve in ship pipeline system

\section{Calculation Results and Discussion}

Before applying the boundary load, the Waters design method $^{[4]}$ was adopted to get the maximum pre tightening force $(7351.58 \mathrm{~N})$ for four bolts required for rubber seal under working pressure $2.5 \mathrm{MPa}$ according to the flange connection standard. The three dimensional finite element model of the rubber joint established was divided the mesh and given the material parameters. Then two kinds of boundary conditions were applied to the end of the rubber joint: the axial tensile displacement in $\mathrm{x}$ direction and the periodic axial force in $\mathrm{x}$ direction, meanwhile each situation with internal working pressure 2.5MPa. With the finite element software Abaqus, the calculation results were as follows.

\subsection{Axial Tensile Displacement}

As the geometric structure of rubber joint and results obtained were symmetrical about $\mathrm{X}$ and $\mathrm{Y}$ axis, 1/8 part of the rubber joint was used to demonstrate the results. The distributions of Mises stress and principal strain about the rubber skeleton were shown in figures 3 and 4 respectively. The maximum Mises stress and the maximum principal strain in the tensile direction ( $\mathrm{X}$ axis) identified in fig. 3 and fig. 4 were all located at rubber end face pressed by the adapting flange. Furthermore, the Mises stress and the principal strain in tensile direction in area 1 for rubber skeleton see fig. 3 and fig.4, which was the vicinity area contacted with the fastening flange, were apparently higher than that in the other regions. The maximum Mises stress and strain for each components of rubber joint were illustrated in Table 2. It can be seen from table 2 that the sequence of the maximum Mises stress from large to small for each 
component was reinforcing rings, cord fabric, the rubber end face contact with the adapting flanges, and rubber zone 1 contact with the fastening flanges. Comparatively speaking, the Mises stress of reinforcing rings and cord fabrics was larger. The principal strain distribution on the rubber joint was similar to the stress distribution.

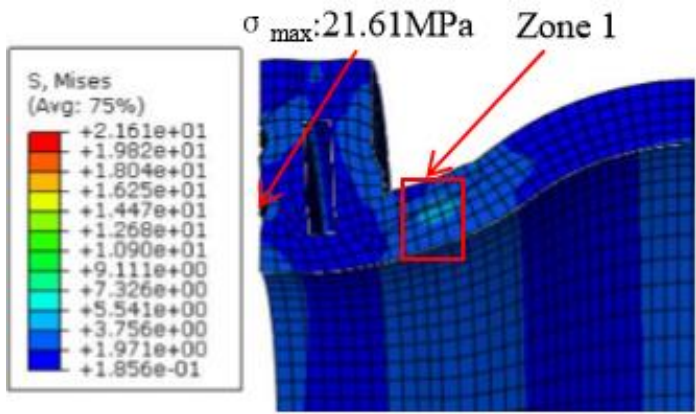

Figure 3 Stress cloud chart of rubber framework
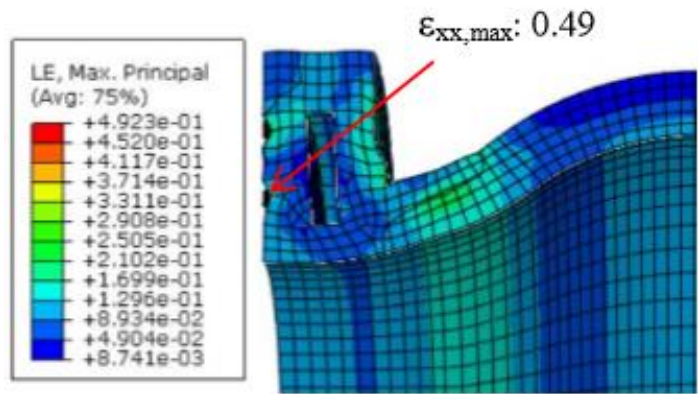

Figure 4 Principle strain in tensile direction of rubber framework

Table 2 Maximum Mises stress and Principal Strain for each components of rubber joint (Axial tension displacement)

\begin{tabular}{|c|c|c|c|c|c|c|}
\hline \multirow{2}{*}{$\begin{array}{c}\text { Compo } \\
\text {-nents }\end{array}$} & \multicolumn{2}{|c|}{$45^{\circ} /-45^{\circ}$} & \multicolumn{2}{|c|}{$30^{\circ} /-30^{\circ}$} & \multicolumn{2}{|c|}{$60^{\circ} /-60^{\circ}$} \\
\hline & $\begin{array}{l}\sigma_{\max } / \\
\text { Мpa }\end{array}$ & $\begin{array}{l}\varepsilon_{\mathbf{X x}, \max } \\
\times 10^{-2}\end{array}$ & $\begin{array}{l}\sigma_{\max } / \\
\text { Mpa }\end{array}$ & $\begin{array}{l}\varepsilon_{x x, \max } \\
\times 10^{-2}\end{array}$ & $\begin{array}{l}\sigma_{\max } / \\
\text { MPa }\end{array}$ & $\begin{array}{l}\varepsilon_{\mathbf{x x}, \max } \\
\times 10^{-2}\end{array}$ \\
\hline $\begin{array}{c}\text { Reinfor } \\
\text { ci-ng } \\
\text { Rings }\end{array}$ & 525.4 & 0.26 & 738.1 & 0.36 & 329.8 & 0.16 \\
\hline $\begin{array}{c}\text { Rubber } \\
\text { Frame }\end{array}$ & 21.61 & 49 & 20.34 & 48 & 25.52 & 52 \\
\hline Zone 1 & 7.30 & 31 & 3.64 & 16 & 1.87 & 10 \\
\hline $\begin{array}{c}\text { Cord } \\
\text { Fabrics }\end{array}$ & 100.7 & 4.6 & 131.1 & 6.0 & 79.04 & 3.6 \\
\hline
\end{tabular}

\subsection{Periodic Axial Force}

Fig 5 and Fig. 6 show the results of the Mises stress and the principal strain in tensile direction of the rubber frame calculated under the combined action of the periodic axial force and internal pressure 2.5 $\mathrm{MPa}$. Compared with the results in section3.1, the sequence of the maximum Mises stress and strain from large to small for each component was the same as that in section 3.1, see table 3.

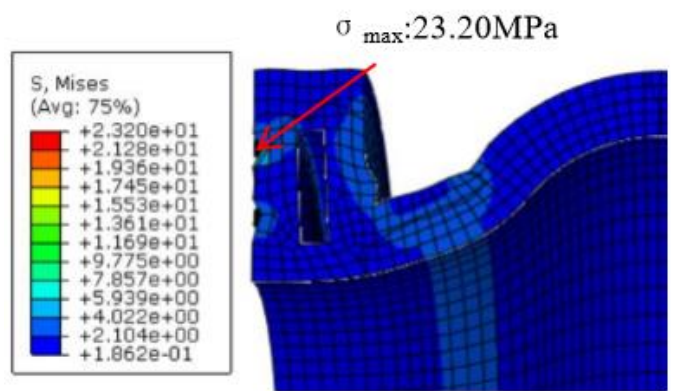

Figure 5 Stress cloud diagram of rubber frame

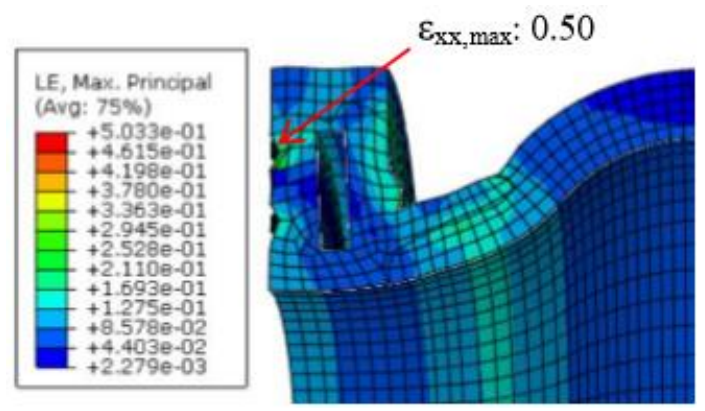

Figure 6 Strain cloud diagram of rubber frame

Table 3 Maximum Mises stress and Principal Strain for each components of rubber joint (Periodic Axial force)

\begin{tabular}{|c|c|c|c|c|c|c|}
\hline \multirow{2}{*}{$\begin{array}{c}\text { Compo- } \\
\text { nents }\end{array}$} & \multicolumn{2}{|c|}{$45^{\circ} /-45^{\circ}$} & \multicolumn{2}{|c|}{$30 \%-30^{\circ}$} & \multicolumn{2}{|c|}{$60^{\circ} \%-60^{\circ}$} \\
\hline & $\begin{array}{l}\sigma_{\max } / \\
\text { MPa }\end{array}$ & $\varepsilon_{\mathrm{xx}, \max } x$ & $\begin{array}{l}\sigma_{\max } / \\
\text { MPa }\end{array}$ & $\varepsilon_{\mathrm{xx}, \max } \mathrm{10^{-2 }}$ & $\begin{array}{l}\sigma_{\max } / \\
\text { MPa }\end{array}$ & $\varepsilon_{x x, \max } x$ \\
\hline $\begin{array}{c}\text { Reinforci-ng } \\
\text { Rings }\end{array}$ & 410.3 & 0.20 & 532.0 & 0.26 & 316.7 & 0.15 \\
\hline $\begin{array}{l}\text { Rubber } \\
\text { Frame }\end{array}$ & 23.29 & 50 & 22.96 & 50 & 25.76 & 52 \\
\hline Zone 1 & 5.04 & 25 & 3.58 & 18 & 1.96 & 11 \\
\hline $\begin{array}{c}\text { Cord } \\
\text { Fabrics }\end{array}$ & 92.90 & 4.2 & 95.68 & 3.9 & 73.46 & 3.3 \\
\hline
\end{tabular}

\section{Fatigue Life Prediction for Rubber Joint}

From the stress results of cord layers, the stresses of the fourth to sixth layers near the flanges were larger. In order to improve this situation, the angle of the cord layer $1,3,5 / 2,4,6$ was adjusted to two cases: $30 \%$ $30^{\circ}, 60^{\circ} /-60^{\circ}$ respectively under the same external load conditions and calculation results were shown in Table 2 and table 3 correspondingly. At the case of angle of $60^{\circ}$ $1-60^{\circ}$, the maximum stress of the reinforcement ring dropped significantly, and the maximum stress in the rubber zone 1 dropped, although the Mises stress of the rubber skeleton and the cord layer increases slightly for two types of boundary load, see fig. 7 .

The results from finite element calculation under periodic axial force above were imported into the elastomer fatigue characteristic software FE-SAFE ${ }^{[5,6]}$. The material fatigue parameters for rubber framework, cord layer, reinforcing ring and flanges, fastening bolts were set to $1.2,390,215$ and $178 \mathrm{MPa}$ respectively. 


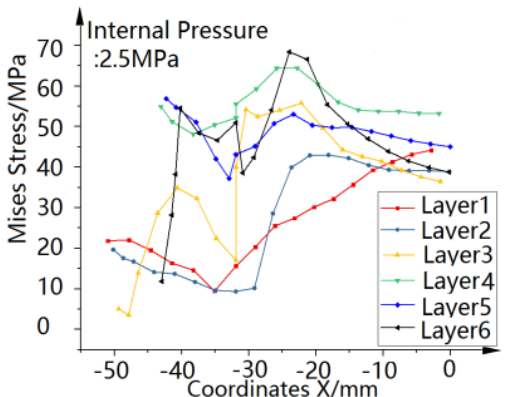

(a)

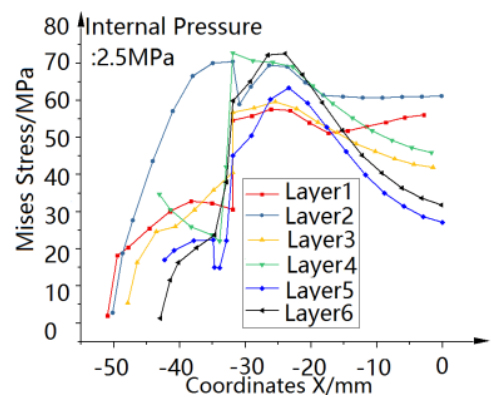

(b)

Figure7 Mises stress distribution along symmetric axis of the rubber joint for six cord fabrics. (a) cord angle $45^{\circ} /-45^{\circ}$ (b) cord angle $60^{\circ}-60^{\circ}$

The minimum cycle number of each component was used as the fatigue life of the component, and the fatigue life of the rubber joint was determined by the minimum life of the component. The fatigue life of each component of the rubber joint under axial cyclic force was calculated, see Table 4.

Table 4 Fatigue life of the rubber joint components (cycle times)

\begin{tabular}{|c|c|c|c|c|}
\hline \multirow{2}{*}{$\begin{array}{c}\text { Angles of } \\
\text { Cord } \\
\text { Layers }\end{array}$} & \multicolumn{2}{|c|}{$\mathbf{2 . 5} \mathrm{MPa}$} & \multicolumn{2}{c|}{$\mathbf{1 2 0 \%} \times \mathbf{2 . 5} \mathbf{M P a}$} \\
\cline { 2 - 5 } & ${\mathbf{4 5} \%-45^{\circ}}^{\circ}$ & $\mathbf{6 0}^{\circ}-\mathbf{6 0}^{\circ}$ & $\mathbf{4 5}^{\circ}-\mathbf{4 5}^{\circ}$ & $\mathbf{6 0}^{\circ}-\mathbf{6 0}^{\circ}$ \\
\hline $\begin{array}{c}\text { Reinforci- } \\
\text { ng Rings }\end{array}$ & 1905460.72 & $>10^{7}$ & 816582.37 & $>10^{7}$ \\
\hline $\begin{array}{c}\text { Rubber } \\
\text { Frame }\end{array}$ & 72443.60 & 51522.86 & 63533.09 & 51050.5 \\
\hline $\begin{array}{c}\text { Cord } \\
\text { Fabrics }\end{array}$ & 30.83 & 990.83 & 22.59 & 151.71 \\
\hline
\end{tabular}

It can be seen from table 4 that the fatigue life of the cord layer was the shortest among all parts of the rubber joint. Increasing the cord angle can increase the life of the reinforcing ring and cord layer, although the fatigue life of the rubber skeleton would decrease a little. Because the minimum life of the joint was determined by the shortest life parts in the whole assembly, changing the cord angle helps prolong the service life of the rubber joint. Increasing the internal pressure to $120 \%$, it could see that the cord layers angle arrangement $60 \%-60^{\circ}$ could still improve the service life of the rubber joint, see table 4.

\section{Conclusions}

By using finite element method, the stress and strain of the components of rubber joints were calculated under the combined action of internal pressure and axial tension or cyclic force. In order to reduce the local stress of the rubber joint, the fatigue life of each component was computed by introducing the finite element results calculated into the fatigue life software. And the component life with the shortest life span was regarded as the rubber joint life. On the basis of the above outcome, the following conclusions were obtained:

Under the action of axial tension displacement load or periodic force, the sequence of the maximum stress and strain at tensile direction for the rubber joint components from large to small was the reinforcing ring, the cord layer, the faces of rubber skeleton contacted with the flanges.

The stresses for six layers of cord were different. The cord stress increased with the increase of radial radius of the joint. The change of cord angle would vary the stress of the reinforcing ring, the maximum stress member. By increasing the cord angle, the maximum stress of the reinforcement ring could be reduced to improve the stress distribution of it and the cord layer and prolong the fatigue life of both components, thereby extending the life of the rubber joint.

\section{Acknowledgements.}

The Authors thank the support from CHEMCLOUDCOMPUTING@BUCT.

\section{References}

1. Dongjie Liu, Shixiong Zheng. Analysis of Vibration Isolation and Noise Reduction of Piping System for Secondary Pumping Station with Flexible Rubber Joints[J].Water Technology,2012,6(1):149-153.

2. Youhua Shao, Zhenhua Zhang. Analysis of Transverse Impact Characteristics of Flexible Double-ball Rubber Joints[J].Noise and Vibration Control,2012,1:2-5.

3. Yifei Xue,Xiaoxiang Yang. Analysis of Pipe Structure Vibration of Reciprocating Compressors by Finite Element Method [J].Fujian Chemical Industry, 2002, (4):56-73.

4. Jinyang Zheng,Qiwu Dong,Zhifu Sang. Process Equipment Design [M]. Third Edition. Beijing: Chemical Industry Press, 2013.135-140

5. Fanzhu Li, Jinpeng Liu,Haibo Yang, et al. Finite Element Analysis of Uniaxial Tensile Fatigue Life Prediction of Rubber Materials[J]. Rubber Industry, 2015, 62(7): 439-442.

6. Zhenhui Tian,Yuyan Liu,Zhimin Wan,et al. Experimental Study on Fatigue Failure of Polyester Reinforced Rubber[J].Journal of Materials Engineering,2000(4):34-37. 